\title{
Cuidado e construção social da pessoa: contribuiçóes para uma teoria geral
}

\author{
| ${ }^{1}$ Vania Bustamante, ${ }^{2}$ Cecilia Mccallum |
}

Resumo: O presente trabalho tem como objetivo realizar uma reflexão conceitual sobre o cuidado. Após desenvolver uma revisão da literatura, que se detém especialmente no trabalho de Ayres, defendese a necessidade de pensar duas grandes maneiras de compreender o cuidado na área da saúde: de um lado, o cuidado constitui um horizonte normativo que orienta as práticas de saúde; de outro, tal como é mostrado com dados etnográficos, cuidado envolve a construção cotidiana de projetos de pessoa que se dá em um marco de relações de poder. O primeiro é um conceito inspirador para a construção de boas práticas de saúde. O conceito aqui proposto nos aproxima do cotidiano, de práticas de cuidado construídas por pessoas nos mais diversos contextos. Ambos os conceitos estão ligados à perspectiva ontológica do Cuidado e são fundamentais para a construção de uma teoria geral sobre o cuidado.

> Palavras-chave: cuidado em saúde; cuidado infantil; horizonte normativo; construção social da pessoa.

\author{
1 Instituto de Psicologia, \\ Universidade Federal da Bahia. \\ Salvador-BA, Brasil. Endereço \\ eletrônico: vaniabus@yahoo.com \\ ${ }^{2}$ Faculdade de Filosofia \\ e Ciências Humanas/ \\ Antropologia. Universidade \\ Federal da Bahia. Salvador-BA \\ Brasil. Endereço eletrônico: \\ cecilia.mccallum@uol.com.br
}




\section{Introdução}

No presente estudo, buscamos refletir teoricamente sobre o Cuidado. Este é um tema muito presente na produção acadêmica na área da saúde, especialmente na Saúde Coletiva, que tem como objeto de estudo os múltiplos aspectos envolvidos nos processos de saúde-doença-cuidado (ALMEIDA FILHO, 2000).

Almeida Filho (2000) chama a atenção para a dificuldade em definir "saúde" e a tendência a fazê-lo em relação a sua falta. Argumenta-se aqui que também há dificuldade para definir "cuidado", assim como a tendência a propor definiçõos universalizantes, como a ideia de cuidado como "ato de vontade, de solidariedade, de generosidade" (AQUINO; MENEZES, 1998, p. 141), ou atreladas ao senso comum. Nesse sentido, Anéas e Ayres (2011) chamam a atenção sobre a existência de modos cindidos e separados de considerar o cuidado em saúde:

O senso comum considera o cuidado em saúde como "[...] um conjunto de procedimentos tecnicamente orientados para o bom êxito de um certo tratamento" (AYRES, 2004a, p.74). Tal entendimento mantém a noção de cuidado em torno dos recursos e medidas terapêuticas e, também, nos procedimentos aplicados (ANÉAS; AYRES, 2011, p. 652).

Para desenvolver a argumentação sobre o cuidado neste artigo, é pertinente citar o trabalho de Thomas (1993), que na sua análise sobre a categoria mostra que há vários conceitos que dependem do interesse dos pesquisadores. A referida autora argumenta que o cuidado é uma categoria problemática na medida em que existem definições muito restritas ou muito amplas. Neste sentido, uma definição ampla de cuidado incluiria toda forma de trabalho centrado nas pessoas. Ao sinalizar esses problemas, a autora argumenta que o cuidado é uma categoria empírica que para ser estudada requer ser relacionada com categorias teóricas. No presente trabalho, tenta-se dar resposta aos desafios apontados por Thomas.

Visando contribuir para a reflexão teórica sobre o cuidado, e mais especificamente sobre o cuidado infantil, no presente estudo são abordadas diferentes formas de entender este termo e para isso dialoga-se com diversos autores. Com base em uma revisão crítica da literatura sobre cuidado em saúde, e na análise de dados etnográficos, propõe-se diferenciar entre duas grandes formas de conceituar cuidado. De um lado, o cuidado constitui um horizonte normativo para as práticas de saúde, e o desenvolvimento desta perspectiva tem expressão muito significativa na obra de Ayres. Por outro lado, o cuidado não 
tem uma qualidade definida a priori, e se constrói cotidianamente em interações

que envolvem relações de poder. É possível encontrar aspectos dessa perspectiva em vários autores, e no presente trabalho apresenta-se uma argumentação que busca integrar contribuiçôes anteriores. Assim, a proposta deste artigo vai ao encontro da discussão de Almeida Filho (2011) sobre a necessidade de uma discussão teórica em torno da saúde na perspectiva de uma teoria geral:

[...] se conceituarmos os fenômenos da saúde-doença como processos sociais e se
aceitarmos o suposto de que processos sociais são históricos, complexos, fragmen-
tados, orgânicos, corporais, conflitantes, dependentes e incertos, então precisamos
gerar dispositivos interpretativos mais adequados para referenciar, com o devido ri-
gor, os objetos da pesquisa científica em saúde. Para isso, torna-se urgente conceber
e utilizar abordagens capazes de fazer justiça à natureza complexa e múltipla dos
processos concretos relativos a vida, a aflição, sofrimento, dor, doença, cuidado, cura
e morte - a saúde, enfim, que ocorrem em agregados humanos históricos (ALMEIDA
FILHO, 2011, p. 13).

Assim como Ayres (2004A, p. 74), defende-se aqui a centralidade da discussão sobre o cuidado para pensar as práticas de saúde: "É nessa condição de uma desconstrução teórica com vistas a contribuir para a reconstrução em curso nas práticas de saúde, que se quer trazer ao debate a presente reflexão sobre o Cuidado”.

O presente estudo foi originado com base em uma tese de doutorado sobre o cuidado infantil que envolveu a realização de pesquisa etnográfica em bairro de baixa renda de Salvador (BUSTAMANTE, 2009). O projeto foi aprovado pelo Comitê de Ética em Pesquisa do Instituto de Saúde Coletiva da UFBA (Registro 035-06/CEP-ISC). Alguns dados etnográficos são retomados aqui para ilustrar nossa compreensão conceitual sobre o cuidado.

\section{Estudos sobre cuidado e saúde}

A seguir se apresenta uma revisão de literatura sobre o cuidado que, embora não seja exaustiva e priorize a produção brasileira, permite identificar e refletir sobre diferentes maneiras de compreender e usar este termo.

O termo "cuidado" é frequentemente utilizado na discussão sobre integralidade e humanização das práticas de saúde. Ao refletir sobre a Política Nacional de Humanização da Atenção e da Gestão na Saúde (PNH), Benevides e Passos (2005, p. 392) apontam que a humanização "se constrói com as direções da inseparabilidade entre atenção e gestão e da transversalidade", e como o fazer desta política se concretiza como "tecnologias relacionais", onde a inseparabilidade 
das práticas de cuidado e de gestão do cuidado é central. No entanto, apesar de chamar a atenção sobre a centralidade do cuidado, esses autores não refletem sobre o conceito em si mesmo.

Identificamos uma situação parecida na discussão de Pinheiro e Mattos (2005) sobre a integralidade como um dos princípios do SUS. Os autores consideram que integralidade e cuidado são temas com grande potencial para pesquisa e também são artefato estratégico de debate no âmbito da Saúde Coletiva. Nesse sentido, destacam que o cuidado é uma categoria-chave para abrir novos diálogos do campo de conhecimentos, saberes e práticas em saúde, possibilitando a concretude de ações que se destinam a materializar uma política de saúde em defesa da vida. Contudo, eles não refletem sobre o que é cuidado.

Oliveira (2008, p. 347) apresenta uma "proposta de discussão e de construção teórico-metodológica sobre o complexo tema dos modelos de cuidados à saúde”, apontando a possibilidade de que se efetive na articulação de ensino-serviço. Isto possibilitaria a "construção conjunta para abordagens dos modelos de cuidados" (p. 347), o que seria um dos eixos estruturantes nas diretrizes curriculares da formação de profissionais em confluência com a reorientação do sistema assistencial brasileiro. A autora esclarece que não tem como objetivo realizar uma reflexão teórica sobre o cuidado e destaca que o grande objetivo das práticas de saúde é a construção da integralidade no cuidado e na atenção á saúde. O termo "cuidado" parece estar sendo utilizado em um sentido descritivo ou de senso comum. De outro lado, existem estudos sobre o cuidado na enfermagem. Alguns trabalhos partem do pressuposto de que o cuidado é o que caracteriza o trabalho do enfermeiro (SOUZA et. al., 2006) e refletem sobre a necessidade de melhorar a formação do enfermeiro no que diz respeito ao cuidado (ver CAMACHO; ESPÍRITO SANTO, 2001).

Existem numerosos estudos sobre práticas de cuidado à saúde em diferentes grupos: Falceto et al. (2008) desenvolveram um estudo quantitativo sobre a participação do pai nos cuidados ao lactente; Padilha et al. (2007) refletiram sobre práticas de não cuidado na perspectiva dos clientes hospitalares; Grippo e Fracolli (2008) realizaram avaliação sobre os efeitos de uma cartilha sobre cuidados a crianças nas mães; Lourenço e Deslandes (2008) estudaram o cuidado materno em mulheres vítimas de violência durante a gestação; Frota et al. (2007) desenvolveram uma pesquisa-ação sobre educação popular em saúde no cuidado 
à criança desnutrida; Silva e Tokumaru (2008) exploraram cuidados parentais

e aloparentais recebidos por crianças de escolas públicas e particulares. Esses trabalhos têm em comum a ausência de discussão conceitual sobre o cuidado.

Identificam-se alguns estudos empíricos que exploram a compreensão que as pessoas têm sobre cuidado a partir da análise do que elas dizem. Nesse sentido, Crepaldi et al. (2006) estudam a participação do pai no cuidado na perspectiva da mãe e destacam que nem tudo o que o pai faz com a criança é considerado cuidado por parte da mãe. Soares e Coelho (2008) desenvolveram um estudo qualitativo sobre o cotidiano do cuidado infantil em comunidades rurais da Bahia, buscando compreender o sentido e os valores sociais e culturais que direcionam essa prática no cotidiano. Borges e Japur (2005) analisaram o uso do termo "cuidado" em conversas com usuárias do Programa de Saúde da Família (PSF); identificaram diferenças entre os sentidos propostos pelo discurso hegemônico - principalmente associado com a unidade frequentada pelas participantes da pesquisa - e aquele produzido pelos usuários, que demandam diferentes tipos de cuidado em saúde a depender do momento da vida em que se encontram. As autoras consideram que existe polissemia de discursos sobre os cuidados em saúde e que é preciso desnaturalizá-los enquanto discurso único, considerando sua referência a contextos sociais.

Os referidos estudos avançam ao procurar compreender o que é cuidado para os participantes da pesquisa e relacionar a compreensão sobre o cuidado com as condições de vida, refletindo sobre as possíveis implicações práticas dos resultados. Isto é mais claro no trabalho de Rodrigues et al. (2008), envolvendo um estudo empírico sobre representação social do cuidado no PSF em Natal. Os autores identificam que o cuidado é representado como atenção, amor e acolhimento e sugerem levar em consideração o referido núcleo central das representações sobre o cuidado na formação e capacitação dos profissionais de saúde.

O caráter sócio-histórico do cuidado como algo que se opõe a uma perspectiva universalizante sobre o mesmo é destacado por alguns autores. Por exemplo, Martinez (2006) descreve transformações históricas do cuidado à criança no México e as relaciona com diferentes formas de pensar a infância. Por outro lado, estudos tanto na saúde quanto na educação chamam a atenção sobre a histórica associação entre cuidado e natureza feminina. Assim, para Scavone (2005, p. 102), “os cuidados pela saúde não são fruto de uma determinação biológica entre 
os sexos, mas sim das relações sociais de sexo/gênero". Para a autora, o cuidado é um tipo de trabalho que se dá nas esferas pública e privada e, na medida em que os cuidados femininos à saúde da família estão associados à expressão de afeto, é difícil que sejam reconhecidos como trabalho. De acordo com a referida autora, a oposição entre care (cuidar) e cure (curar) desvaloriza o cuidar em si, expurgando-o do campo médico profissional e restringindo-o ao campo do privado, afetivo, familiar - logo, do não profissional.

Esta curta revisão vai ao encontro da percepção de Gutierrez e Minayo (2011) sobre a dificuldade de construir reflexóes teóricas sobre o cuidado. Como parte de uma revisão teórica de estudos sobre cuidado da saúde no âmbito da família, as autoras identificaram uma "tendência de adoção de conceitos de cuidado abrangentes, que sintetizam aspectos materiais, afetivos e sociais sem, no entanto, uma discussão em termos concretos" (p. 1.497). Outro aspecto apontado é "a escassez de estudos sobre os modos de cuidar da saúde no âmbito da família, que explorem as ações efetivamente realizadas, as representações associadas a essas ações, bem como as negociações para distribuição das tarefas por seus diferentes membros" (p. 1.499). Poucos textos trazem uma análise teórica do conceito de cuidado e na maioria dos trabalhos o cuidado é indicado como "noção que atinge várias dimensões das relações entre os seres humanos" (p. 1.500). As autoras apontam a necessidade de pensar em cuidados em saúde na família diminuindo "o foco da família como entidade abstrata para concentrá-la na participação das mulheres e homens enquanto agentes concretos" (p. 1.506). A discussão conceitual que se desenvolve a seguir pretende dar resposta às inquietações dessas autoras. $\mathrm{E}$, como parte desse caminho, é preciso apresentar as contribuições de Ayres.

\section{Cuidado como horizonte normativo para as práticas de saúde}

Ayres e alguns colaboradores vêm discutindo o cuidado nas práticas de saúde de forma densa e consistente. $\mathrm{O}$ autor defende que a reflexão sobre o cuidado é central em um contexto de crise das práticas de saúde que, ao priorizarem as tecnociências, não estão dando resposta às necessidades de saúde das pessoas. Diante desta crise, surgem iniciativas que visam a mudanças. Ayres (2001) faz referência à humanização, à Estratégia de Saúde da Família e à vigilância da saúde; destaca a importância da reflexão teórica para repensar as práticas de 
saúde, optando pela filosofia, principalmente a obra de Heidegger em relação ao cuidado. Nesse sentido, Anéas e Ayres (2011) chamam a atenção sobre o caráter ontológico do cuidado:

[...] a compreensão do que é cuidado em saúde, tal como o compreendemos aqui, desdobra-se de uma compreensão ontológica do Cuidado, já como efeito da própria ontologia fundamental que faz dele o elemento central para a compreensão da existência humana. Dito de outra forma, a concepção de cuidado em saúde que se vê como possibilidade para as práticas de saúde só é possível porque, antes de tudo, se assume o Cuidado em seu sentido ontológico (p. 654).

Não se tem como objetivo aqui aprofundar a discussão sobre a obra de Heidegger, mas é preciso deixar claro de que modo Ayres o toma como ponto de partida para pensar sobre o cuidado. Nesse sentido, Anéas e Ayres (2011, p. 653) destacam que "o cuidado em sentido ontológico quer dizer: o homem sempre cuida. Mesmo nas relações de desprezo e descuido, o homem cuida”. Desta maneira, considerando-se o Cuidado em sentido ontológico, o cuidado em saúde, como uma ação do Dasein é um desdobramento. Daisen se refere à indissociabilidade entre homem e mundo: "A constituição fundamental do Daisen é ser no mundo" (ANÉAS; AYRES, 2011, p. 653).

Em trabalho publicado em 2004, Ayres aponta que o cuidado pode ser pensado em quatro sentidos: como categoria ontológica, genealógica, reconstrutiva e crítica. Em relação ao cuidado como categoria ontológica, Ayres (2004a) recupera a alegoria do cuidado - que está presente no livro de Heidegger Ser e tempo - e destaca aspectos relevantes para a discussão acerca do cuidado no âmbito específico da saúde. $\mathrm{O}$ autor identifica e descreve as principais condições presentes na alegoria: movimento - nossas identidades vão sendo construídas no e pelo ato de pôr-se em movimento pelo mundo; interação - as interações constroem a trama; identidade e alteridade - as identidades existenciais só se estabelecem no ato mesmo dessas interações; a plasticidade-da matéria possibilita a criação, dissolução, finitude e recriação do ser vivente; desejo - nenhum dos personagens age de forma completamente determinada. É do encontro desejante com as circunstâncias que se origina o ser vivente; temporalidade - "é sempre na perspectiva do fluxo do tempo que faz sentido falar de cuidado..." (p. 47); responsabilidade - pois o conhecimento do mundo é já um modo de ser no mundo, e não um distanciamento do mesmo; projeto - o Ser do humano é cuidado. É projetar e, ao mesmo tempo, ser o "curador" do projeto. Assim, 
"Cuidar não é só projetar, é um projetar responsabilizando-se; um projetar porque se responsabiliza” (2001, p. 49). O autor aponta que esses elementos são reencontrados ao pensar no cuidado nas práticas de saúde e inclusive propõem que o modo de ser do cuidado possa ser usado como princípio para uma avaliação formativa das práticas de saúde (ver AYRES, 2004c).

Em relação ao conceito foucaultiano do "cuidado de si", Ayres (2004a) destaca que enquanto "Heidegger possibilitou-nos uma autocompreensão existencial da condição humana como cuidado, Foucault nos mostra o desenvolvimento do cuidado de si como uma forma de vida no ocidente cristão" (p. 81). As dimensões crítica e reconstrutiva do cuidado são explicitadas no mesmo ensaio e são mais desenvolvidas em outros trabalhos. O cuidado como categoria crítica envolve: "Cuidado como modo de interação nas e pelas práticas de saúde nos seus moldes contemporâneos [...] tecnologias já configuradas como o campo institucional das práticas de saúde” (AYRES, 2004a, p. 81).

O cuidado como categoria reconstrutiva supōe pensar que: "revalorizar a dignidade dessa sabedoria prática é, portanto, uma tarefa e um compromisso fundamental quando se quer Cuidar" (AYRES, 2004a, p. 86). Nesse sentido, Ayres aponta três motivações fundamentais para pensar no cuidado e os desafios da reconstrução das práticas de saúde: 1) voltar-se à presença do outro; 2) otimizar a interação; e 3) enriquecer horizontes. Esses desafios implicam que "os novos discursos permitam efetivamente reconstruir nossas práticas de saúde para que possamos sempre mais chamá-las de Cuidado" (2004a, p. 90). Assim, no marco das práticas de saúde, o autor considera que o Cuidado pode ser definido como:

[...] designação de uma atenção à saúde imediatamente interessada no sentido existencial da experiência do adoecimento, físico ou mental, e, por conseguinte, também das práticas de promoção ou recuperação da saúde (p. 90).

Em um trabalho em que reflete sobre os desafios para a humanização das práticas de saúde o autor aponta para "alguns aspectos que podem fazer de um encontro terapêutico uma relação de Cuidado, desde uma perspectiva que busque ativamente relacionar o aspecto técnico, aos aspectos humanistas da atenção à saúde" (AYRES, 2004b, p. 18). Para isso, traz o relato do contato com uma usuária a quem chama de Dona Violeta, com quem "delicada e bem-sucedida relação de cuidado aconteceu” (p. 18). Tratava-se de uma paciente hipertensa, atendida em uma unidade básica, que poderia ter sido como todos os anteriores - a paciente se 
queixa do tempo de espera e do seu estado físico, usa a medicação, mas esta não

dá o resultado clínico esperado, o profissional a ouve de forma rotineira - se não fosse o médico resolver olhar de outra forma para o próprio cansaço e irritação: pediu que ela falasse um pouco sobre si mesma. Diante deste estímulo, a paciente narrou a própria vida, e se construiu um encontro terapêutico que Ayres (2004b) considerou uma prática humanizada e uma situação de Cuidado, pois nela houve um encontro intersubjetivo que envolveu a reflexão sobre projetos de felicidade. $\mathrm{O}$ médico sugeriu à paciente que escrevesse sua história de vida. Este passou a ser um projeto para a paciente. $\mathrm{O}$ autor destaca que para construir este momento de Cuidado o médico, utilizou-se de sabedorias práticas que estavam além do conhecimento técnico sobre hipertensão. Nesse sentido, Anéas e Ayres (2011, p. 659) destacam que:

O genuíno encontro no cuidado é possível a partir da disponibilidade de uma escuta que traz a pessoalidade do Dasein. O profissional se abre a esta escuta, não como porta-voz do discurso instrumental, mas como aquele que acolhe o outro e torna as suas demandas válidas para o direcionamento de suas intervençôes. O cuidado se dá em um contínuo das relações entre usuários e serviços de saúde, em todas as oportunidades que se faça possível entender aquilo que o outro traz em relação à sua existência.

Ao refletir sobre modelos de atenção à saúde, Ayres (2009) faz referência ao cuidado como uma dimensão da técnica que é fundamental na perspectiva da integralidade, que “nos desafia a saber e fazer o 'quê' e 'como' pode ser realizado em saúde para responder universalmente às necessidades de cada um” (p. 21), e que isto requer de saberes intermediários e saberes práticos. O cuidado é uma noção central para pensar na técnica e, nesse sentido:

A ideia de cuidado vem justamente tentar reconstruir, a partir dos problemas e tensões apontados, uma atenção integral à saúde de indivíduos e comunidade, buscando recompor competências, relações e implicações ora fragmentadas, empobrecidas ou desconexas (AYRES, 2009, p. 18).

Nesse trabalho, o autor aponta que antes de tentar uma definição do cuidado, é mais importante apontar princípios e procedimentos que se afinem com o mais importante do que se quer resgatar com o conceito de cuidado: "trata-se de fazer mais e, algumas vezes, um pouco diferente, aquilo que já sempre terá feito parte da arte da atenção à saúde” (AYRES, 2009, p. 18). Também se trataria de ouvir mais, ver mais, tocar mais: estas práticas são benéficas para alcançar o "êxito técnico" que simultaneamente deverá se configurar como "sucesso prático": 
"resposta adequada aos modos como estes [usuários e comunidades] entendem que deve ser a vida e saúde no seu cotidiano".

Ayres (2001) destaca que o saber dirigido ao êxito técnico constrói objetos, enquanto o saber voltado ao sucesso existencial é aquele que constitui sujeitos. Neste sentido, subsumir a ideia de êxito técnico ou de "produção de artefatos" pela de "sucesso existencial" é parte fundamental da sua proposta. O "sucesso existencial" pode se conectar ao conceito de "projeto de felicidade", onde a felicidade é considerada uma experiência de caráter singular e pessoal, que ao mesmo tempo está associada a valores publicamente aceitos como propiciadores desta experiência (AYRES, 2004b).

Ainda segundo Ayres (2001), se o horizonte normativo, que norteia o discurso dos profissionais de saúde, está fundamentalmente relacionado à utopia do conhecimento/controle das doenças, há que se perguntar se é possível imaginar o compartilhamento entre os profissionais e as populaçóes-alvo. $\mathrm{O}$ autor destaca que não se deve diminuir a importância do controle da enfermidade, mas deve ser revista sua exclusividade como critério normativo de sucesso das práticas de saúde. Ele chama a atenção sobre a tendência dos profissionais de saúde a se aterem à negatividade da doença, deixando de lado a dimensão existencial: "nós, efetivamente, não temos nos perguntado, quando dialogamos sobre saúde, sobre o que sonham as pessoas (nós mesmos) para a vida, para o bem viver, para a saúde...” (AYRES, 2001, p. 71). O autor propõe que para cuidar da saúde é fundamental construir projetos, saber qual o projeto de felicidade que está em questão no ato assistencial, perguntando-nos que papel desempenham os cuidadores na possibilidade de conceber essa felicidade em termos de saúde.

A noção de "projeto de felicidade" é proposta como uma espécie de horizonte normativo implicado na noção de cuidado. Isto implica que é necessário não só o conhecimento das ciências biomédicas e os conhecimentos oriundos das ciências humanas:

Vamos especialmente precisar usar a sabedoria prática, ou seja, precisaremos fundir horizontes entre nossos saberes técnicos e os saberes que as pessoas de quem cuidamos acumularam sobre si próprias e seus projetos de felicidade, com a abertura necessária para que, do diálogo entre esses saberes, surjam boas escolhas sobre o quê e como fazer nas diversas situações de cuidado (AYRES, 2009, p. 19).

A proposta de Ayres (2009) traz contribuições imprescindíveis para refletir sobre o que é desejável nas práticas de saúde. Entretanto, ao colocar cuidado 
como horizonte normativo, não deixa espaço para compreender práticas que não

se dão dentro desse horizonte. Sobre essa dimensão, refletimos a seguir.

\section{Cuidado infantil, projetos e construção social da pessoa}

Argumenta-se aqui que cuidado infantil envolve a construção de projetos de pessoa em práticas cotidianas que se dão em um marco de relações de poder. $\mathrm{O}$ conceito proposto está inspirado na perspectiva de Ayres, porém incorporando uma perspectiva etnográfica e sociocultural - partindo, portanto, de conceitos nativos e considerando as diferenças de classe, raça/cor/etnia, geração e as diferenças de gênero.

Para entender as práticas e conceitos que compõem o cuidado para as pessoas que o constroem cotidianamente, é necessário entender a noção de pessoa que está em jogo. A pessoa é o foco principal do cuidado. A antropologia fornece ferramentas cruciais para pensar a noção de pessoa (McCALLUM; BUSTAMANTE, 2012). Resumidamente, Pina Cabral (2007), ao questionar o "cesurismo" que, nos passos de Dumont (1993), pressupõe uma dicotomia entre modernos e tradicionais (onde apenas o Ocidente alcançou a condição moderna), sugere dissolver a oposição entre sociedades tradicionais baseadas no holismo e sociedades modernas fundadas no individualismo. O problema das abordagens cesuristas é que apenas outorgam plena pessoalidade e agência individual e autonomia àqueles tidos como plenamente "modernos", sendo que pessoas de camadas baixas, áreas rurais, ou etnias marginalizados, por serem considerados "tradicionais!", não alcançam plenamente a condição de individuo ou "pessoa" nos padrôes da modernidade. Pina-Cabral (2007), ao discordar desta visão, considera que a pessoa se constrói na relação com o outro, que não há um indivíduo ou pessoa antes de haver uma relação com o outro - ou seja, que a alteridade precede a identidade.

Para Pina Cabral (2007), o holismo e o individualismo não são excludentes; ambos estão presentes na construção social da pessoa e nesse sentido não existe teoricamente qualquer simetria entre os conceitos de pessoa e indivíduo. O autor considera que o holismo é essencial à constituição das pessoas, e é sobre ele que se assentam diferentes formas de sociabilidade, na medida em que "todo ser humano só é humano na medida em que se insere em uma relação com outros seres humanos" (p. 108). Desta maneira, argumenta-se aqui que a pessoa se constrói permanentemente em processos de individuação e interdependência. 
A ideia de projeto que se defende aqui está apoiada nas contribuições de Rabelo (1999). No contexto de uma pesquisa com portadores de doença mental em um bairro popular de Salvador, Rabelo (1999) recupera o conceito de projeto de Schutz, integrando-o às reflexões de Merleau Ponty sobre o corpo vivido. Destaca que, para Schutz, projetar é: "antecipar uma conduta futura por meio da fantasia. Entretanto, diferente da mera fantasia, projetar implica a intenção de realizar o projeto e, portanto, requer que sejam levadas em consideração certas limitações impostas pela realidade sobre a qual se quer agir" (RABELO, 1999, p. 207). Assim, o ator formula um projeto do ponto de vista da sua situação biográfica particular, lançando mão de conhecimentos acerca de atos já realizados que se assemelham ao que pretende desenvolver. Entretanto, nem as circunstâncias em que estes atos foram realizados permanecem as mesmas, nem o próprio sujeito, que necessariamente adquiriu novos conhecimentos e experiências durante o transcurso temporal da realização do projeto. Todo projeto, portanto, guarda uma quantidade essencial de indeterminação.

A autora destaca que pensar no projeto como fantasia não envolve uma concepção mentalista, segundo a qual o sujeito primeiro pensa e depois age no mundo: "os projetos formulam-se à luz dos propósitos práticos que decorrem da situação biográfica particular do ator ou do curso das suas experiências mundanas" (RABELO, 1999, p. 208). O sujeito busca transcender sua situação via projeto. É com base na perspectiva que o corpo fornece que nos orientamos no espaço. O corpo é diferente dos outros objetos com os quais lidamos no cotidiano; ele se confunde com nosso próprio ser. Isso implica que "a subjetividade é em si mesma instigada pelo corporal, mundano. Por outro lado, significa também que o corpo é perpassado por uma dimensão subjetiva, de sentido: é corpo vivido" (RABELO, 1999, p. 209). Há uma unidade corpo/mente, onde "ao mesmo tempo em que é retrato de uma trajetória anterior de escolhas, projetos e experiências, o corpo é também movimento contínuo para a realização de projetos presentes" (RABELO, 1999, p. 208). Assim, "ter um corpo é para uma pessoa viva juntar-se a um meio definido, confundir-se com alguns projetos e engajar-se continuamente neles" (MERLEAU-PONTY apud RABELO, 1999, p. 209). O projeto é construído no e por meio do corpo e se desenvolve e desdobra em novas facetas. Assim, "pode-se dizer que o corpo torna mais real o projeto, não só para os outros como para o próprio indivíduo que o formula" (p. 209). 
A experiência encarnada de aflição constitui o ponto de partida para a elaboração de projetos de normalidade nos indivíduos pesquisados por Rabelo. Em nenhum caso houve uma sequência linear, iniciada na formulação mental do projeto e concluída em sua execução corporal. Pelo contrário, o corpo se antecipa a essa atividade reflexiva: "no curso de sua realização no corpo, o projeto adquire precisão, assume contornos antes não vislumbrados e abre novos caminhos para uma exploração ativa da situação" (RABELO, 1999, p. 224). A autora destaca que:

Projetos não consistem simplesmente em elaborações abstratas de um sujeito desprendido e momentaneamente independente do seu meio; mas, antes, em práticas situadas, forjadas em contextos de ação/atenção perante as coisas. Para entendê-los, argumentou-se, é preciso recuperar a dimensão corporal que perpassa toda a experiência de ser-no-mundo (p. 224).

Defendemos que cuidado envolve construção de projetos no sentido destacado por Rabelo (1999) - de práticas forjadas em contextos de ação/ atenção perante as coisas - relacionadas com a criança como pessoa. Para ilustrar o conceito proposto aqui, utilizaremos material etnográfico de um estudo sobre o cuidado infantil.

Em Prainha, nome fictício de um bairro de baixa renda de Salvador, através de cuidados corporais cotidianos, os adultos que cuidam da criança visam ao mesmo tempo dar ao corpo da criança sua forma adequada e construí-la como indivíduo singular e como pessoa relacional, com sua "natureza" dominada. As seguintes notas de campo são ilustrativas de como o cuidado é permanente e se dá em atividades cotidianas, especialmente as que envolvem lidar com o corpo:

Fui visitar Dona Rita. Fiquei com receio de ser inconveniente, pois era quase o horário de preparar as crianças para a escola. Cheguei à porta e ouvi Viviane, a neta dela de sete anos, gritando. Aí João, o filho dela de 11 anos, disse que eu podia entrar. Dona Rita estava com um pente na mão e estava gritando com Viviane. Ela me viu, mandou entrar, e me explicou que Viviane está muito "retada", que ela tem uma natureza ruim, que não obedece, que quer impor a vontade dela. Como parte dos preparativos para a escola, Dona Rita tinha dado banho na neta e depois penteou seu cabelo. Deixou presa a parte alta e colocou enfeites. Viviane não gostou e começou a tirar, porque gosta de usar o cabelo solto. Dona Rita acha isso uma coisa muito ruim e começou a bater nela. Ela pensa que Viviane não deve ficar com cabelo solto, porque fica muito embaralhado e depois é muito difícil de pentear. Perguntei por que é que ela era dessa natureza ruim. E Dona Rita falou: "Ah, juntou o pai com o avô, porque o pai dela também tem esse gênio forte". Bom, aí Dona Rita falou que não deixa Viviane fazer as vontades dela, mesmo, que é melhor fazer isso agora que ela é pequena, e que por isso que ela "bate mesmo" (Notas de campo). 
Este episódio é um momento de cuidado onde existem projetos de pessoa. Não se trata simplesmente de resolver um problema prático. O que está em jogo é muito mais do que tornar mais fácil a tarefa diária de pentear o cabelo de Viviane. É preciso que o cabelo seja comprido - Viviane usa o cabelo comprido, assim como a maioria das meninas de Prainha -, o qual torna a tarefa de pentear mais árdua, mas ao mesmo tempo o cabelo bem penteado adquire visibilidade quanto mais comprido - ou mais “duro" - for. Para Dona Rita, é inaceitável que a neta vá à escola com o cabelo solto, isto seria expressão de uma "natureza ruim".

Outros aspectos materiais fazem parte da rotina de se preparar para ir à escola. Viviane deve tomar banho, vestir a farda e comer a comida que a avó servir. A higiene é particularmente valorizada por Dona Rita, que falou sobre isso durante outra visita:

Dona Rita começou a me dizer que gosta muito de arrumar. Viviane tem o prato dela, o copo dela, João tem as coisas dele também. E que ela acha que é assim, que o adulto deve ter as suas coisas, e criança as suas coisas também. Que cada um tem o seu sabonete, sua toalha. E ela me mostrou os produtos de Viviane para o cabelo: xampu, condicionador, creme de pentear e creme de tratamento. Disse que o pai tinha comprado tudo da mesma linha. Ela falou assim: "A gente já não tem nada, então a gente não pode ser porco, a gente tem que arrumar tudo". E ela disse que a roupa também, ela lava tudo separado. Ela sabe que não tem nenhuma doença, mas ela lava as calcinhas dela por um lado, as calcinhas de Viviane por outro. Pensa que a pele da criança é muito sensivel. Então pode pegar logo coisas do adulto (Notas de campo).

Duas questôes chamam a atenção neste relato: a preocupação de Dona Rita com a higiene - do corpo e dos objetos usados no corpo, como as roupas - e como isto é feito: separando os objetos que pertencem a cada indivíduo. Por um lado, Dona Rita busca "dominar a natureza" da neta, fazendo com que esta aceite os cuidados que dão ao seu corpo a forma adequada. Ao dominar sua natureza, Dona Rita constrói a neta como indivíduo singular que precisa ter seus próprios objetos, especialmente aqueles com os quais constrói sua realidade corporal. Para "não ser porco" é preciso separar os corpos, inclusive através do uso individualizado de produtos de higiene e de se lavar as roupas separadamente.

$\mathrm{O}$ cuidado que Dona Rita oferece à neta se da cotidianamente, para além do que é pensado, e está ligado a uma noção de pessoa que tem a ver com questôes de classe, nesse sentido com relações de poder. A afirmação de Dona Rita - " $A$ gente já não tem nada, então a gente não pode ser porco" - pode ser relacionada com a discussão de Dalsgaard (2006) sobre a procura de reconhecimento por parte 
de mulheres de baixa renda. A referida autora descreve os enormes esforços das mulheres por mostrar um corpo limpo e bem arrumado - especialmente quando se trata de frequentar serviços de saúde, como uma tentativa de obter melhor tratamento por parte dos profissionais. Em Prainha, os moradores comentam que para que um profissional examine com detalhe: "Tem que levar a criança limpinha, se não eles não olham".

Para pensar na noção de relações de poder em que os projetos de pessoa são cotidianamente construídos, utiliza-se aqui a perspectiva de Bourdieu (1989), que defende que a realidade se constrói a partir de relações dentro do espaço social, que por sua vez se organiza em campos sociais com características próprias. Segundo o autor, as tomadas de posição, ou escolhas dos agentes, se dão em um espaço de posições sociais - relacionadas com a estrutura de distribuição de diferentes tipos de capital - que são mediadas pelo espaço de disposições ou habitus. Para o autor, os princípios de construção do espaço social são as diferentes espécies de poder ou de capital que ocorrem em diferentes campos, onde o campo econômico tende a impor sua estrutura aos outros. No entanto, cada campo tem sua lógica e hierarquia próprias, de maneira que os agentes se distribuem nele segundo o volume de capital que possuem e segundo "o peso relativo das diferentes espécies dentro das suas posses” (BOURDIEU, 1989, p. 134).

Por motivos de espaço, aqui não será possível desenvolver as possibilidades de compreensão do cuidado, especialmente do cuidado infantil, que estão atreladas à conceitualização apresentada, e que foram amplamente desenvolvidas em estudo etnográfico sobre a construção cotidiana do cuidado infantil em um bairro popular de Salvador. O que se quer destacar é a existência dos vários conceitos de cuidado possíveis.

Retomando o relato sobre Dona Violeta, dentro da perspectiva aqui defendida, houve diferentes práticas de cuidado em todos os momentos da atenção, pois existiam projetos de pessoa em forma implícita. Ao mesmo tempo, o momento em que o terapeuta muda a maneira de lidar com a paciente, e isto transforma o vínculo, constitui uma prática que se humaniza a partir da perspectiva do cuidado como horizonte para as práticas de saúde. Desta maneira, pensar no cuidado como construção de projetos de pessoa nos permite compreender e contextualizar diversas situações de cuidado, assim como refletir sobre como são construídas as diferenças entre os cuidadores. 


\section{Considerações finais: para uma teoria geral do cuidado}

Tanto a noção de cuidado como horizonte normativo para as práticas de saúde, quanto o conceito de cuidado como construção de projetos de pessoa são desdobramentos do Cuidado no sentido ontológico - segundo o qual o homem sempre cuida, mesmo nas relaçóes de desprezo e descuido. O primeiro é um conceito inspirador para a construção das práticas de saúde. $\mathrm{O}$ conceito aqui proposto nos aproxima do cotidiano, de práticas construídas nos mais diversos contextos. Nesse sentido, defendemos a importância de que esta maneira de compreender o cuidado seja considerada como sabedoria prática que pode ser incluída nas práticas de saúde.

Dá-se resposta à lacuna apontada na literatura ao mostrar que é possível refletir teoricamente, considerando, ao mesmo tempo, que o cuidado é sempre diferente, pois é construído cotidianamente. Dentro desta perspectiva, será preciso continuar desenvolvendo estudos etnográficos sobre as práticas de cuidado em diversos contextos. $\mathrm{E}$ isso poderá contribuir para ampliar a compreensão sobre a diversidade de maneiras de cuidar, assim como sobre os diversos fatores que influenciam as práticas. Isto, por sua vez, poderá ajudar a diminuir o fosso que separa os profissionais, e de algum modo também aos pesquisadores, dos usuários.

Para finalizar, vale a pena retomar a afirmação de Almeida Filho (2011, p. 148) sobre a necessidade de construir uma teoria geral sobre a saúde, que é diferente de uma teoria unificada, pois “implica modos alternativos de compreensão, respeitando a complexidade dos objetos e a pluralidade das distintas aproximaçóes científicas de um problema interdisciplinar”. Assim como não é suficiente um conceito positivo de saúde, também é insuficiente a compreensão positiva do cuidado. Espera-se ter contribuído para pensar uma teoria geral do cuidado. Certamente se trata de um primeiro trabalho que deverá ser aprofundado em novos estudos que possam incluir publicações mais recentes e ampliar o escopo para a produção internacional. ${ }^{1}$

\section{Referências}

ALMEIDA-FILHO, N.A. A ciência da saúde. São Paulo: Hucitec, 2000. O que é saúde? Rio de Janeiro: Fiocruz, 2011.

ANÉAS, T.V.; AYRES, J.R.C.M. Significados e sentidos das práticas de saúde: a ontologia fundamental e a reconstrução do cuidado em saúde. Interface, Comunicação, saúde, educação, Botucatu, v. 15, n. 38, p. 651-662, set. 2011. 
AQUINO, E.; MENEZES, G. Para pensar no exercício da paternidade: contribuições a partir de um estudo sobre trabalho e saúde de mulheres. In: SILVEIRA, P. (Org.). Exercício da paternidade. Porto Alegre: Artes Médicas, 1998. p. 131-141.

AYRES, J.R.C.M. Cuidado e reconstrução das práticas de saúde. Interface: Comunicação, Saúde, Educação. Botucatu, v. 8, n. 14, p. 73-92, set/fev 2004 a.

. Norma e formação: horizontes filosóficos para as práticas de avaliação no contexto da promoção da saúde. Ciência e Saúde Coletiva. Rio de Janeiro, v. 9, n. 3, p. 583-592, set. 2004c.

. O Cuidado, os modos de ser (do) humano e as práticas de saúde. Saúde e Sociedade. São Paulo, v. 13, n. 13, p. 16-29, set/dez 2004b.

. Organizações das ações de atenção à saúde: modelos e práticas. Saúde e Sociedade. São Paulo, v. 18, n. 2, p. 11-23, jun. 2009.

Sujeito, intersubjetividade e práticas de saúde. Ciência e Saúde Coletiva. Rio de Janeiro, v. 6, n. 1, p. 63-72, 2001.

BENEVIDES, R.; PASSOS, E. Humanização na saúde: um novo modismo? Interface: Comunicação, Saúde, Educação. Botucatu, v. 9, n. 17, p. 389-394, mar/ago. 2005.

BORGES, C.; JAPUR, M. Promover e recuperar a saúde: sentidos produzidos em grupos comunitários no contexto do Programa de Saúde da Família. Interface: Comunicação, Saúde, Educação. Botucatu, v. 9, n. 18, p. 507-519, set/dez. 2005.

BOURDIEU, P. Razões práticas: sobre a teoria da ação. Campinas: Papirus, 1996.

CAMACHO, A.C.L.F.; ESPÍRITO SANTO, F.H. Refletindo sobre o cuidar e o ensinar na enfermagem. Revista Latino-Americana de Enfermagem. Ribeirão Preto, v. 9, n. 1, p. 13-17, jan 2001.

CREPALDI, M.A. et al. A participação do pai nos cuidados da criança, segundo a concepção de mães. Psicologia em Estudo. Maringá, v. 11, n. 3, p. 579-587, set/dez 2006.

DALSGAARD, A.L. Vida e esperanças: esterilização feminina no Nordeste. São Paulo: UNESP, 2006.

DUMONT, L. Individualismo: uma perspectiva antropológica da ideologia moderna. Rio de Janeiro: Rocco, 1993.

FALCETO, O.G. et al. Fatores associados ao envolvimento do pai nos cuidados do lactente. Revista de Saúde Pública. São Paulo, v. 42, n. 6, p. 1034-1040, mai 2008.

FROTA, M.A. et al. Educação popular em saúde no cuidado à criança desnutrida. Texto contexto: Enfermagem. Florianópolis, v. 16, n. 2, p. 246-253, abr/jun 2007.

GRIPPO, M.L.V.S.; FRACOLLI, L.A. Avaliação de uma cartilha educativa de promoção ao cuidado da criança a partir da percepção da família sobre temas de saúde e cidadania. Revista Escola de Enfermagem USP. São Paulo, v. 42, n. 3, p. 430-436, set 2008. 
GUTIERREZ, D.M.D.; MINAYO, M.C.S. Produção de conhecimento sobre cuidados da saúde no âmbito da família. Ciência e Saúde Coletiva. Rio de Janeiro, v. 15, n. 1, p. 14971508, jun 2010.

LOURENÇO, M.A.; DESLANDES, S.F. Experiência do cuidado materno e amamentação sob a ótica de mulheres vítimas de violência conjugal. Revista de Saúde Pública. São Paulo, v. 42, n. 4, p. 615-621, jul/ago 2008 .

MARTINEZ, J.G. Uma joya preciosa: significado del cuidado del niño en México. Texto e Contexto: Enfermagem, Florianópolis, v. 15, n. especial, p. 146-151, jun 2006.

McCALLUM, C.; BUSTAMANTE, V. Parentesco, gênero e individuação no cotidiano da casa em um bairro popular de Salvador da Bahia. Etnográfica, Lisboa, v. 16, n. 2, p. 221246, jun 2012.

OLIVEIRA, M.C. Os modelos de cuidados como eixo de estruturação de atividades interdisciplinares e multiprofissionais em saúde. Revista Brasileira de Educação médica, Rio de Janeiro, v. 32, n. 3, p. 347-355, jul/set 2008.

PADILHA, M.I.C.S. et al. Significados das práticas de não cuidados na visão dos clientes hospitalares. Revista Brasileira de Enfermagem, Brasília, v. 57, n. 6, p. 724-728, nov/dez 2004.

PINA-CABRAL, J. A pessoa e o dilema brasileiro: uma perspectiva anticesurista. Novos Estudos Sebrap. São Paulo, v. 78, p. 95-111, jul. 2007.

PINHEIRO, R.; MATTOS, R.A. Cuidado e integralidade: vida, conhecimento, saúde e educação. In: _______. (Orgs.). Cuidado: as fronteiras da integralidade. 3. ed. Rio de Janeiro: Cepesc, 2006. p. 7-9.

RABELO, M. C. A experiência de indivíduos com problema mental: entendendo projetos e sua realização. In: RABELO, M.C.; ALVEZ, P.C.; SOUZA, I.A. (Org.). Experiência de doença e narrativa. Rio de Janeiro: Fiocruz, 1999, p. 205-227.

RODRIGUES, M.P. et al. A representação social do cuidado no Programa Saúde da Família na cidade de Natal. Ciência e Saúde Coletiva. Rio de Janeiro, v. 13, n. 1, fev. 2008.

SCAVONE, L. O trabalho das mulheres pela saúde: cuidar, curar, agir. In: VILELA, W.; MONTEIRO, S. (Org.). Gênero e Saúde: Programa de saúde da família em questão. Rio de Janeiro: Abrasco, 2005, p.99-110.

SILVA, L.W.; TOKUMARU, R. Cuidados parentais e aloparentais recebidos por crianças de escolas públicas e particulares de Vitória-ES. Psicologia Reflexão e crítica. Porto Alegre, v. 21, n.1, p. 133-141, 2008.

SOARES, M.D.; COELHO, T.C.B. O cotidiano do cuidado infantil em comunidades rurais do Estado da Bahia: uma abordagem qualitativa. Revista Brasileira de Saúde MaternoInfantil. Recife, v. 18, n. 6, p. 463-472, out/dez 2008. 
SOUZA, A.C.C. et al. Formação do enfermeiro para o cuidado: reflexões da prática profissional. Revista Brasileira de Enfermagem, Brasília, v; 59, n. 6, p. 805-807, nov/dez 2006. THOMAS, C. De-constructing concepts of care. Sociology. London, v. 27, n. 4, p. 649-669, nov. 1993.

\section{Nota}

${ }^{1}$ Este trabalho é um desdobramento da tese de doutorado da primeira autora, orientada pela segunda.

V.Bustamante escreveu uma primeira versão deste manuscrito e C. McCallum participou da revisão e produção da última versão. 


\section{Care and the social construction of the person:} contributions towards a general theory

This study aims to conduct a conceptual reflection on care. After reviewing the literature, with a special focus on the work of Ayres, we argue that it is necessary to think in two major ways to understand care in the sphere of health: on the one hand, care is a normative horizon that guides health practices; on the other, as we show through ethnographic discussion, care involves the daily construction of projects of the person within a framework of power relations. The former is an inspirational concept for the building of good health practices. The concept proposed here brings us closer to everyday life, to the practices of care people develop in a great diversity of contexts. Both concepts are linked to the ontological perspective of Care and are fundamental to the construction of a general theory of care.

- Key words: health care; child care; normative horizon. 